American Journal of Pharmaceutical Education 2021; 85 (2) Article 8083.

\title{
RESEARCH
}

\section{The Impact of Two Longitudinal Professionalism Courses on Student Pharmacists' Empathy}

\author{
Brent N. Reed, PharmD, ${ }^{a}$ Stuart T. Haines, PharmD, ${ }^{b}$ Erin R. Holmes, PharmD, PhD ${ }^{b}$ \\ ${ }^{a}$ University of Maryland, School of Pharmacy, Baltimore, Maryland \\ ${ }^{\mathrm{b}}$ University of Mississippi, School of Pharmacy, Jackson, Mississippi \\ Submitted April 3, 2020; accepted October 30, 2020; published February 2021.
}

Objective. To determine whether empathy increased in first-year student pharmacists after completing longitudinal professionalism courses at two schools of pharmacy, identify potential moderators, and assess whether students' conceptualization of empathy changed with time.

Methods. Surveys to assess empathy and other variables were administered to student pharmacists at baseline and at the end of two professionalism courses. Baseline and follow-up scores were compared to detect changes over time. Multivariable analysis was used to identify predictors of empathy scores. Factor analysis was performed to ascertain changes in the dimensionality of empathy.

Results. Students' demographics and baseline empathy scores differed between the two schools. Predictors of empathy at baseline included age, female gender, prior health care experience, and altruism score. A small increase in empathy was observed at one school but not in the combined cohort. Empathy was more likely to increase among female students, those with less health care experience, and those who did not work during the school year. Factor analyses suggested that students' conceptual clarity about empathy improved over time and became more consistent with existing models.

Conclusion. Although an increase in empathy was not observed in the overall cohort, subgroups of students who may derive greater benefit from empathy-related interventions were identified. Factor analyses suggested that students' conceptual understanding of empathy improved, representing a potential alternative outcome assessment for affective domains. Given differences in demographics, instructional methodologies, and changes in empathy at each school, this study reinforces the importance of replication and multicenter studies to understand the generalizability of educational research.

Keywords: pharmacy, empathy, instructional methods, assessment

\section{INTRODUCTION}

Building a covenantal relationship with patients requires that pharmacists demonstrate a variety of interpersonal attitudes and behaviors, which are commonly aggregated under the construct of professionalism. ${ }^{1-4}$ Accordingly, Standard 4 of the 2016 Accreditation Council for Pharmacy Education (ACPE) Standards (Standards 2016) requires that schools of pharmacy inculcate professional attitudes and behaviors in student pharmacists. ${ }^{5}$ Implicit in Standards 2016 is that these attributes can be developed, yet few examples exist of educational interventions that have a sustained impact on students' professional attitudes and behaviors. The purpose of this study was to determine whether one such attribute, empathy, could be positively influenced in

Corresponding Author: Brent N. Reed, University of Maryland School of Pharmacy, 20 N. Pine St., Office S428, Baltimore, MD 21201. Tel: 410-706-1452. Email: breed@ rx.umaryland.edu student pharmacists following enrollment in a longitudinal professionalism course.

Empathy is consistently recognized as a core tenet of professionalism and necessary for fulfilling the responsibilities of a health care professional. ${ }^{1-4}$ We used the definition of empathy proposed by Hojat (sometimes referred to as clinical empathy or cognitive empathy): "a predominantly cognitive (rather than an affective or emotional) attribute that involves understanding (rather than feeling) of the patient's experiences, concerns, and perspectives, combined with a capacity to communicate this understanding, and an intention to help." ${ }^{\prime 6}$ Studies have shown that educational interventions may confer a short-term increase in empathy among student pharmacists, but these effects are not sustained..$^{7-10}$

We were also interested in whether other constructs might influence changes in empathy over time; these were altruism, self-awareness, grit, and locus of control. Altruism and self-awareness are also considered core tenets 


\section{American Journal of Pharmaceutical Education 2021; 85 (2) Article 8083.}

of professionalism, and the latter is thought to provide a gauge by which students self-evaluate professional attitudes and behaviors. ${ }^{2,5}$ Grit has received considerable interest in academia and pharmacy education. ${ }^{11-13}$ However, one criticism of grit as a target of instruction is that it overlaps with conscientiousness and may therefore be dispositional in nature. ${ }^{14}$ The latter is also thought to be true of locus of control, which, to our knowledge, has not been previously studied in student pharmacists. Locus of control refers to the degree to which individuals attribute their life circumstances to self (internal) or outside forces (external).

The intervention employed in this study was a twosemester professionalism course at two US schools of pharmacy, during which empathy, altruism, self-awareness, grit, and locus of control were addressed. In addition to measuring whether empathy increased over time, we also sought to explore whether students' understanding of the construct and its dimensionality would change. We expected for empathy to be positively related to altruism based on prior research and for self-awareness to moderate changes in empathy. ${ }^{15,16}$ In terms of dispositional constructs, we expected that students with an internal locus of control would be less likely to demonstrate empathy as they might view patient's life circumstances and health status as a product of the patient's lifestyle and behaviors. ${ }^{17}$ Similarly, we hypothesized that "grittier" individuals would be less likely to empathize with patients who cannot overcome these challenges. Finally, we sought to determine whether demographic characteristics moderated changes in empathy over time.

\section{METHODS}

Participants were first-year Doctor of Pharmacy (PharmD) students enrolled in professionalism courses at the University of Maryland School of Pharmacy (UMD) or the University of Mississippi School of Pharmacy (UMS) during the 2018-2019 academic year. Validated survey instruments to measure each construct were administered prior to the first class of the fall semester (baseline) and again at the end of the spring semester (follow-up). Students were required to complete the surveys for course credit as results were used in class exercises, but they could opt out of having their results used for research. The study was deemed exempt by institutional review boards at both campuses.

At UMD, the course met weekly across both semesters. Course content consisted primarily of active learning and students were required to review pre-class materials ahead of each session. Preparation was incentivized by the instructors making "cold calls" on students during class, ie, a random list of students was generated for each class and when a student was called upon, they lost credit if they were absent or unprepared to answer the instructor's question. Each of the above constructs was covered during at least one class session. For the session on empathy, students were introduced to the biopsychosocial model of health and differences between affective and cognitive empathy. Students then participated in an exercise in which they were asked to discuss their "highs" and "lows" from the past week with a partner. Students were tasked with attempting to discern the underlying feelings and unmet needs expressed by their partner, as well as the empathic listening behaviors they used. The session concluded with a discussion of strategies to improve such behaviors and their impact on the patient experience. Empathy was later revisited as a self-reflection assignment and covered on the final examination.

At UMS, the course met every other week for two semesters. In addition to responding to open-ended questions using an in-class audience response system, students completed a series of learning activities for each course segment. For example, in the fall, students were required to write an essay about professionalism and professional identity following an in-class series on professionalism during which each of the constructs of interest was discussed. In the spring, students completed a series of self-assessment instruments related to personality type, learning style, personal strengths, and wellbeing. Subsequently, following a presentation about selfawareness and reflection, students were required to write a reflective essay about the results of these inventories and relationships to their goals. Additionally, students completed a pharmacy practice laboratory with an empathic communication exercise. Students were required to achieve a passing level of performance on all course activities according to instructor-developed rubrics. Examinations were not administered to assess performance.

Empathy was measured using The Jefferson Scale of Empathy for Health Professions Students (JSE-HPS), an instrument validated for use with students in several health disciplines, including among student pharmacists. ${ }^{6,7,18-20}$ The JSE-HPS consists of 20 statements (eg, "Health care providers should try to stand in their patients' shoes when providing care to them"), for which respondents indicate their level of agreement on a Likerttype scale. The remaining constructs were also measured using Likert-type scales. Altruism was measured using a subscale from Podsakoff's organizational citizenship behavior questionnaire. ${ }^{21}$ Self-awareness was measured using the awareness of self subscale from the Perceived Choice and Awareness of Self Scale (PCASS). ${ }^{22}$ Grit was measured using the Short Grit Scale (Grit-S), an 


\section{American Journal of Pharmaceutical Education 2021; 85 (2) Article 8083.}

instrument previously used in studies of student pharmacists. ${ }^{12,13,23}$ Locus of control was measured using the brief version of the Levenson locus of control (LoC) scale. ${ }^{24}$ Finally, students were asked to provide information regarding demographic characteristics, work experience, and socioeconomic status. The latter was ascertained by asking respondents to report household income and a rating on the MacArthur Scale of Subjective Social Status. ${ }^{25}$ Surveys were administered online using Qualtrics XM (Qualtrics).

Sample characteristics were analyzed using descriptive statistics, and the chi-square, Fischer exact test, or $t$ test were used to compare students' responses between the two campuses. Interrelationships were analyzed using Pearson $r$. Baseline and follow-up scores were compared using repeated-measures analysis of variance (ANOVA), and mixed model ANOVA was used to compare the two campuses. Effect sizes were calculated using the Cohen's $d$ or partial $\eta^{2}$. Multivariable regression was performed to identify predictors of construct scores. Variables tested at baseline were age, gender, minority status, socioeconomic status, prior health care experience, and construct scores. Follow-up models also included school attended and whether students worked during the school year.

Exploratory factor analysis (EFA) and confirmatory factor analysis (CFA) was performed based on prior empathy research. ${ }^{26-28}$ The combined cohort was divided into two paired groups at baseline and follow-up such that each paired group was similar in terms of demographics or construct scores. At each time point, EFA was performed on the first group and CFA on the second. Each EFA was performed using principal axis factoring given the expectedly latent nature of empathy and its underlying components. An oblique (promax) rotation was used for factor extraction, and the number of retained factors was determined via inspection of eigenvalue thresholds and scree plot. Sampling adequacy was assessed using the Kaiser-Meyer-Olkin (KMO) measure and the Bartlett test for sphericity. Each CFA tested three models: a null model, an EFA-based model, and the three-factor model proposed by Hojat and LaNoue. ${ }^{26}$ All analyses were performed using SPSS and SPSS Amos, version 25 (IBM).

\section{RESULTS}

Two hundred thirty-eight students were enrolled in the two courses, 132 at UMD and 106 at UMS (Table 1). All of the students consented to have their responses included in this research. Most students were female (67.6\%). Overall, students at UMD were older than students at UMS (23.9 vs 22.8 years of age; $p<.001)$ and had more health care experience (1.8 vs 1.0 years; $p<.001)$. Racial and ethnic composition also differed between the two campuses $(p<.001)$. Our follow-up sample $(\mathrm{n}=208)$ was smaller because of student attrition, but the demographic composition did not change appreciably.

Baseline means and standard deviations for the constructs of interest are shown in Table 2. As hypothesized, empathy was related to altruism; however, the relationship was weak to moderate $(\mathrm{r}=.37 ; p<.01)$. Empathy was also weakly related to grit $(\mathrm{r}=.19 ; p<.01)$ but not to self-awareness or locus of control. Correlations achieving statistical significance among students at UMD were the same as the overall cohort, although the relationships between variables were generally stronger; at UMS, empathy correlated only with altruism $(r=.27$; $p<.01)$. Students at UMD had a higher mean empathy score than students at UMS $(p=.031)$. In the overall cohort, significant predictors of baseline empathy were age, female gender, prior health care experience, and altruism. Fit for the overall model was significant, $F(4,229)=16.12$ $\left(p<.001 ; \mathrm{r}^{2}=.22\right)$, even after controlling for school, $\mathrm{F}(5,228)=12.99\left(p<.001 ; \mathrm{r}^{2}=.22\right)$.

Follow-up scores are also shown in Table 2. In the overall cohort, empathy did not change compared to baseline scores. A difference in self-awareness emerged, but not in the expected direction. A small decrease was observed compared to baseline $(p<.001 ; \mathrm{d}=.29)$. Locus of control also decreased, ie, became more external $(p<.001)$, but the effect size was small $(\mathrm{d}=.26)$.

When the two schools were examined individually, a small increase in empathy was observed at UMD $(p=.003 ; \mathrm{d}=.28)$, and school attended was a small to moderate moderator of the change in empathy over time $\left(\mathrm{F}(1,206)=6.218 ; p=.013\right.$; partial $\left.\eta^{2}=.03\right)$. Unlike the overall cohort, altruism also increased among students at UMD, but the effect size was very small $(p=.048 ; \mathrm{d}=.18)$. Compared to baseline values, changes in self-awareness, locus of control, and grit among students at UMD were similar to the overall cohort. Among students at UMS, only a small to medium decrease in self-awareness was observed $(p<.001 ; \mathrm{d}=.34)$.

Predictors of follow-up empathy scores were baseline empathy scores, prior health care experience, and school attended. The overall model was significant $(\mathrm{F}(3$, $202)=29.74 ; p<.001 ; \mathrm{r}^{2}=.31$; Table 3 ). In contrast to baseline scores, those with less health care experience were more likely to experience higher empathy scores at follow-up and an increase in empathy over time. Another predictor of an increase in empathy was gender, with an increase in empathy being less likely to occur among men (OR, 0.49; 95\% CI, 0.21-0.85). Subgroup analyses confirmed many of these relationships and included one additional finding: a small increase in empathy observed 
American Journal of Pharmaceutical Education 2021; 85 (2) Article 8083.

Table 1. Characteristics of Student Pharmacists Who Participated in a Study on Whether Empathy Can Be Learned

\begin{tabular}{|c|c|c|c|c|}
\hline Characteristic & Combined $(\mathrm{n}=\mathbf{2 3 8})$ & UMD (n=132) & UMS $(n=106)$ & $p$ Value $^{\mathrm{a}}$ \\
\hline Age, y & $22.8(3.5)$ & $23.9(4.2)$ & $21.4(1.3)$ & $<.001$ \\
\hline \multicolumn{5}{|l|}{ Gender } \\
\hline Male (\%) & $73(30.7)$ & $36(27.3)$ & $37(34.9)$ & .105 \\
\hline Female (\%) & $161(67.6)$ & $92(69.7)$ & $69(65.1)$ & \\
\hline Prefer not to say & $4(1.7)$ & $4(3.0)$ & $0(0)$ & \\
\hline \multicolumn{5}{|l|}{ Race/ethnicity } \\
\hline White or Caucasian (\%) & $128(53.8)$ & $42(31.8)$ & $86(81.1)$ & $<.001$ \\
\hline Asian or Pacific Islander (\%) & $53(22.3)$ & $43(32.6)$ & $10(9.4)$ & \\
\hline Black or African American (\%) & $43(18.1)$ & $34(25.8)$ & $9(8.5)$ & \\
\hline Other $(\%)$ & $14(5.8)$ & $13(9.8)$ & $1(1.0)$ & \\
\hline Prior healthcare experience (years) & $1.4(1.9)$ & $1.8(2.1)$ & $1.0(1.5)$ & .001 \\
\hline Prior pharmacy experience (years) & $1.2(1.7)$ & $1.3(1.8)$ & $1.0(1.5)$ & .104 \\
\hline Socioeconomic status & $6.2(1.8)$ & $6.3(1.7)$ & $6.1(1.9)$ & .539 \\
\hline \multicolumn{5}{|l|}{ Family household income } \\
\hline Less than $\$ 5,000(\%)$ & $2(0.8)$ & $2(1.5)$ & $0(0)$ & .123 \\
\hline$\$ 5,000-\$ 11,999(\%)$ & $1(0.4)$ & $1(0.8)$ & $0(0)$ & \\
\hline$\$ 12,000-\$ 15,999(\%)$ & $2(0.8)$ & $1(0.8)$ & $1(0.9)$ & \\
\hline$\$ 16,000-\$ 24,999(\%)$ & $7(2.9)$ & $4(3.0)$ & $3(2.8)$ & \\
\hline$\$ 25,000-\$ 34,999(\%)$ & $19(8.0)$ & $12(9.1)$ & $7(6.6)$ & \\
\hline$\$ 35,000-\$ 49,999(\%)$ & $18(7.6)$ & $9(6.8)$ & $9(8.5)$ & \\
\hline$\$ 50,000-\$ 74,999(\%)$ & $39(16.4)$ & $22(16.7)$ & $17(16.0)$ & \\
\hline$\$ 75,000$ - \$99,999 (\%) & $22(9.2)$ & $14(10.6)$ & $8(7.5)$ & \\
\hline$\$ 100,000$ and greater $(\%)$ & $87(36.6)$ & $42(31.8)$ & $45(42.5)$ & \\
\hline Prefer not to say $(\%)$ & $15(6.3)$ & $12(9.1)$ & $3(2.8)$ & \\
\hline Don’t know (\%) & $26(10.9)$ & $13(9.8)$ & $13(12.3)$ & \\
\hline \multicolumn{5}{|l|}{ Working during school year ${ }^{\mathrm{b}}$} \\
\hline 0 hours/week (\%) & $94(39.5)$ & $52(39.4)$ & $42(39.6)$ & .994 \\
\hline 1 to 5 hours/week (\%) & $44(18.5)$ & $20(15.2)$ & $24(22.6)$ & \\
\hline 6 to 10 hours/week (\%) & $42(17.6)$ & $29(22.0)$ & $13(12.3)$ & \\
\hline 11 to 20 hours/week (\%) & $23(9.7)$ & $11(8.3)$ & $12(11.3)$ & \\
\hline More than 20 hours/week (\%) & $5(2.1)$ & $2(1.5)$ & $3(2.8)$ & \\
\hline Not reported $(\%)$ & $30(12.6)$ & $18(13.6)$ & $12(11.3)$ & \\
\hline
\end{tabular}

Abbreviations: $\mathrm{UMD}=$ University of Maryland, UMS = University of Mississippi

${ }^{a}$ Refers to comparisons of the two campuses

${ }^{\mathrm{b}}$ Assessed during follow-up survey; cohort sizes were 208 for the combined sample, 114 for the University of Maryland cohort, and 104 for the University of Mississippi cohort

among students who did not work during the school year (3.8 $\pm 13.6 ; p=.007 ; \mathrm{d}=.29)$ but not among those who did.

In the factor analysis of baseline empathy scores, the KMO measure was .77, indicating an adequate sample. Bartlett's test for sphericity indicated data were factorable $\left(\chi_{(190)}^{2}=652.86 ; p<.001\right.$. $)$. Of the initial six-factor solution, two factors were not retained: one because it contained a single item (suggesting it was not stable) and another because it shared loadings with several factors. ${ }^{29}$ Although the fourth factor only contained two items with acceptable loadings, it was retained on the basis that it uniquely predicted variance in prior research. ${ }^{26,28}$ The resulting four-factor solution differed from Hojat and LaNoue's model, which consists of the following three factors: perspective-taking, compassionate care, and walking in a patient's shoes. ${ }^{26}$ In our sample, items traditionally comprising perspective-taking were divided across two factors: one reflected the importance of empathy and the other reflected attitudes toward patient feelings and nonverbal expressions. The third factor resembled compassionate care and the fourth contained the same items as walking in a patient's shoes. In the CFA of baseline scores, the Hojat and LaNoue model demonstrated better fit than ours (Table 4), although the root mean square error of approximation (RMSEA) for both was $>.07$.

For follow-up scores, the KMO measure was .83, suggesting a suitable fit; the Bartlett test for sphericity was $\chi_{(190)}^{2}=1090.11, p<.001$. Only three factors had items with acceptable loadings, and they nearly mirrored 


\section{American Journal of Pharmaceutical Education 2021; 85 (2) Article 8083.}

the Hojat and LaNoue three-factor model. In fact, only item 18 differed in that it loaded on "walking in a patient's shoes." In prior studies, this item had not loaded particularly high on any one factor but had traditionally been categorized within compassionate care. ${ }^{26,28}$ Because it loaded on the former in our sample, we retained it as such for the CFA, which demonstrated almost identical fit parameters as the Hojat and LaNoue model (Table 4). Although neither model achieved an RMSEA $<.5$, the fit was good on all other parameters and considerably better than that of baseline models.

\section{DISCUSSION}

Although several prior studies have demonstrated short-term increases in empathy in student pharmacists following targeted educational interventions (eg, simulation exercises), at least one study suggested that these effects are not sustained. ${ }^{8-10}$ Our study supports the latter in that we did not observe a significant long-term increase in empathy among student pharmacists following completion of longitudinal professionalism courses.

Our work extends what is known about educational efforts to increase empathy in several important ways. First, we observed several factors that appeared to influence baseline levels of empathy and whether the levels increased with time. Baseline empathy scores were higher among older students and those with prior health care experience, suggesting a possible ceiling effect, ie, these subgroups may be less likely to benefit from empathyrelated interventions. Indeed, having less health care experience was a predictor of growth in empathy over time. Additional support for the moderating role of health care experience was found in our subgroup analysis of student employment status, ie, whether they did or did not work during the school year, as the latter were also more likely to experience an increase in empathy over time.

Despite already having higher empathy scores at baseline, women were also more likely to experience an increase over time. These findings align with the results of prior research, including studies of student pharmacists. ${ }^{19,30}$ Differences based on race and ethnicity have been observed among medical students, but these were not observed in our study. ${ }^{31}$ Contrary to our expectations, most of the other phenomena of interest (eg, self-awareness, locus of control) did not appear to influence changes in empathy, with the exception of a weak positive relationship with altruism.

One practical implication of these findings is that opportunities may exist to individualize instruction based on students' prior experiences or baseline levels of empathy. Given the growing number of competencies that schools of pharmacy are expected to develop in student pharmacists (despite limited time and resources), instruction that is intended to build empathy could be targeted to those who need it most. Our study suggests that such interventions are likely to be more effective if they are experiential rather than didactic in nature. Alternatively, schools could emphasize features that predict higher levels of empathy (eg, prior health care experience) during the admissions process.

An alternative explanation for the lack of change in empathy over time may have been the differences in instructional methodology at the two schools. Despite having higher empathy scores at baseline, a small but significant increase was observed among students at UMD. Some of this may have been the result of increased exposure (ie, meeting weekly) or differences in the methods used to incentivize participation (eg, 'cold call',

Table 2. Comparison of Student Pharmacists' Scores on Validated Instruments for Empathy and Other Psychological Constructs

\begin{tabular}{|c|c|c|c|c|c|c|c|c|}
\hline \multirow[b]{2}{*}{ Construct $^{\mathrm{a}}$} & \multicolumn{4}{|c|}{ Baseline Score, Mean (SD) } & \multicolumn{4}{|c|}{ Follow-Up Score, Mean (SD) } \\
\hline & $\begin{array}{l}\text { Overall } \\
(n=238)\end{array}$ & $\begin{array}{c}\text { UMD } \\
(n=132)\end{array}$ & $\begin{array}{c}\text { UMS } \\
(n=106)\end{array}$ & $p$ Value $^{\mathrm{b}}$ & $\begin{array}{l}\text { Overall } \\
(n=208)\end{array}$ & $\begin{array}{c}\text { UMD } \\
(n=114)\end{array}$ & $\begin{array}{c}\text { UMS } \\
(\mathrm{n}=94)\end{array}$ & $p$ Value $^{\mathrm{b}}$ \\
\hline Empathy & $111.5(11.6)$ & $112.5(12.2)$ & $110.3(10.6)$ & .031 & $113.0(14.1)$ & $116.0(13.2)^{\mathbf{c}}$ & $109.3(14.4)$ & .001 \\
\hline Altruism & $22.1(3.1)$ & $22.8(3.1)$ & $.4(3.1)$ & .001 & $22.4(3.6)$ & $23.4(3.4)$ & $21.3(3.5)$ & $<.001$ \\
\hline Self-Awareness & $20.4(3.7)$ & $20.0(4.0)$ & $20.7(3.4)$ & .328 & $19.3(3.8)^{\mathrm{c}}$ & $19.1(4.0)^{\mathbf{c}}$ & $19.5(3.6)^{\mathrm{c}}$ & .504 \\
\hline Grit & $29.2(4.5)$ & $30.1(4.3)$ & $28.0(4.5)$ & $<.001$ & $29.0(4.7)$ & $29.9(4.8)$ & $27.8(4.4)$ & .002 \\
\hline Locus of Control & $47.6(6.9)$ & $48.3(7.3)$ & $46.8(6.2)$ & .038 & $45.7(7.6)^{c}$ & $45.2(8.2)^{\mathbf{c}}$ & $46.3(6.9)$ & .305 \\
\hline
\end{tabular}

Abbreviations: $\mathrm{UMD}=$ University of Maryland, UMS = University of Mississippi

${ }^{a}$ Constructs were measured as follows: empathy was measured using the Jefferson Scale of Empathy for Health Professions Students; altruism was measured using the altruism subscale from Podsakoff's organizational citizenship behavior questionnaire; ${ }^{21}$ self-awareness was measured using the awareness of self-subscale from the Perceived Choice and Awareness of Self Scale; ${ }^{22}$ grit was measured using the Short Grit Scale; locus of control was measured using the brief version of the Levenson locus of control scale. ${ }^{24}$

${ }^{\mathrm{b}}$ For between-school comparison.

${ }^{\mathrm{c}}$ Significant change compared to baseline score (all $p<.01$ ) 


\section{American Journal of Pharmaceutical Education 2021; 85 (2) Article 8083.}

Table 3. Predictors of Empathy Scores Among Student Pharmacists Completing Two Longitudinal Professionalism Courses

\begin{tabular}{|c|c|c|c|}
\hline Time Period & Overall Model & Predictors & Values \\
\hline \multirow[t]{4}{*}{ Baseline } & $\mathrm{F}(4,229)=16.12, p<.001, \mathrm{r}^{2}=.22$ & Age & $\beta=.15, \mathrm{t}(229)=2.52, p=.01$ \\
\hline & & Female gender & $\beta=.24, \mathrm{t}(229)=3.98, p<.001$ \\
\hline & & Prior healthcare experience & $\beta=.13, \mathrm{t}(229)=2.17, p=.03$ \\
\hline & & Altruism & $\beta=.30, \mathrm{t}(229)=4.96, p<.001$ \\
\hline \multirow[t]{3}{*}{ Follow-up } & $\mathrm{F}(3,202)=29.74, p<.001, \mathrm{r}^{2}=.31$ & Baseline empathy & $\beta=.48, t(202)=8.16, p<.001$ \\
\hline & & Prior healthcare experience & $\beta=-.19, \mathrm{t}(202)=-3.04, p=.003$ \\
\hline & & School attended & $\beta=-.25, \mathrm{t}(202)=-4.15, p<.001$ \\
\hline
\end{tabular}

final examination). Combined with important demographic differences between the two schools that appeared to impact empathy scores (ie, age, health care experience), these results underscore the importance of replication in the scholarship of teaching and learning. Consequently, the Academy should encourage researchers to collaborate across multiple institutions in order to understand the generalizability of study results.

Second, although our study illustrates some of the challenges associated with developing professional attitudes and behaviors among student pharmacists (as called for in Standards 2016), it also suggests that learning may occur without changes in attitudes. Student pharmacists' scores on the JSE-HPS (ie, a measure of attitudes) did not increase overall, but factor analysis suggested that the students' conceptualization of empathy became clearer with time. The baseline model in our cohort differed conceptually from that observed in most other studies, including a recent analysis of student pharmacists that extracted only the dimensions of perspective-taking and compassionate care. ${ }^{26,28,32}$ Our follow-up analysis demonstrated conceptual consolidation of these two dimensions and "walking in a patient's shoes," consistent with Hojat and LaNoue's original model. ${ }^{26}$ Although the ultimate goal of Standard 4 is that graduates demonstrate professional attitudes and behaviors, complex constructs such as empathy may be difficult for students to understand, and conceptual clarity may be necessary before changes in attitudes or behaviors occur. Consequently, these constructs should be introduced early in the curriculum so that students can develop a cognitive framework that enables them to build professional attitudes and behaviors over time.

The limitations of our study must be acknowledged. Importantly, our study lacked a control group, making it difficult to discern whether the findings were a consequence of students' course participation. However, the fact that empathy increased in those without prior health care experience and those who did not work during the school year strengthens the argument that some aspect of the pharmacy school experience impacted students' attitudes. Other limitations relate to the instruments used in this study. With the exception of the JSE-HPS, all of the instruments were validated in populations other than student pharmacists. Additionally, our results may have been influenced by social desirability bias, although prior research has shown the JSE-HPS to be particularly resistant to "faking." 33 Finally, our factor analyses are limited by the small sample size relative to prior studies, which included up to thousands of respondents. ${ }^{27,28}$ As a result, our findings should be interpreted as exploratory and hypothesis-generating. Nonetheless, they may provide a more nuanced way of assessing learning related to affective domains.

Table 4. Comparison of Confirmatory Factor Analyses for Empathy Among Student Pharmacists Completing Two Longitudinal Professionalism Courses

\begin{tabular}{lccccccc}
\hline & \multicolumn{3}{c}{ Baseline } & & \multicolumn{3}{c}{ Follow-Up } \\
\cline { 2 - 4 } Model Statistic & Null & Sample & Hojat \& LaNoue & & Null & Sample & Hojat \& LaNoue \\
\hline Chi-square & 764.31 & 256.34 & 252.01 & & 945.68 & 219.78 & 219.09 \\
Chi-square/df & 4.02 & 1.56 & .51 & & 4.98 & 1.32 & 1.31 \\
RMSEA & .15 & .069 & .065 & & .205 & .058 & .057 \\
CFI & 0 & .839 & .852 & & .000 & .930 & .931 \\
TLI & 0 & .814 & .832 & & .000 & .921 & .922 \\
AIC & 804.3 & 348.3 & 338.0 & & 985.7 & 305.8 & 305.1 \\
\hline
\end{tabular}

Abbreviations: $\mathrm{AIC}=$ Akaike information criterion, $\mathrm{CFI}=$ comparative fit index, $\mathrm{df}=$ degrees of freedom, $\mathrm{RMSEA}=$ root mean square error of approximation, TLI=Tucker-Lewis Index 


\section{American Journal of Pharmaceutical Education 2021; 85 (2) Article 8083.}

Although not a limitation per se, one possible critique of our study is that we measured attitudes rather than behaviors. Although the latter are arguably of greater importance, meta-analytic research supports a moderate to strong correlation between attitudes and behaviors, particularly when influenced by social pressures. ${ }^{34}$ Conversely, the definition of empathy used in our study suggests that it may be possible to develop empathic communication skills without changing underlying attitudes. We are not aware of any data in the pharmacy literature to distinguish the two, but their relationship is worthy of future research.

\section{CONCLUSION}

A small increase in empathy scores was observed after completion of a professionalism course at one school but not in the combined cohort of two schools. Younger students and those without health care experience (before matriculation or during the school year) were more likely to experience an increase in empathy over time. Factor analyses suggested that conceptual clarity regarding empathy improved with time (even if it was not accompanied by an increase in empathy scores), which may be an important educational outcome during the first professional year of the PharmD curriculum.

\section{ACKNOWLEDGMENTS}

The authors acknowledge Robert S. Beardsley, $\mathrm{PhD}$, for his contributions to our design and the Asano-Gonnella Center for Research in Medical Education and Health Care at Thomas Jefferson University for allowing us to use the JSE-HPS.

\section{REFERENCES}

1. American Pharmacists Association. Oath of a Pharmacist. Published July 2007. https://www.pharmacist.com/oath-pharmacist. Accessed January 29, 2021.

2. American College of Clinical Pharmacy, Holt SL, Lau MS, et al. Tenets of professionalism for pharmacy students. Pharmacotherapy. 2009;29(6):757-759. doi:10.1592/phco.29.6.757

3. American College of Clinical Pharmacy, Roth MT, Zlatic TD. Development of student professionalism. Pharmacotherapy. 2009; 29(6):749-756. doi:10.1592/phco.29.6.749

4. American Pharmaceutical Association Academy of Students of Pharmacy-American Association of Colleges of Pharmacy Council of Deans Task Force on Professionalism. White paper on pharmacy student professionalism. J Am Pharm Assoc (Wash). 2000;40(1): 96-102.

5. Accreditation Council for Pharmacy Education. Accreditation Standards and Key Elements for the Professional Program in Pharmacy Leading to the Doctor of Pharmacy Degree ("Standards 2016"). Published February 2015. https://www.acpe-accredit.org/ pdf/Standards2016FINAL.pdf. Accessed January 29, 2021. 6. Hojat M. Empathy in Patient Care: Antecedents, Development, Measurement, and Outcomes. New York, NY: Springer; 2007.
7. Van Winkle LJ, Fjortoft N, Hojat M. Impact of a workshop about aging on the empathy scores of pharmacy and medical students. Am J Pharm Educ. 2012;76(1):9. doi:10.5688/ajpe7619

8. Chen AMH, Kiersma ME, Yehle KS, Plake KS. Impact of an aging simulation game on pharmacy students' empathy for older adults. Am J Pharm Educ. 2015;79(5):65. doi:10.5688/ajpe79565 9. Blaszczyk AT, Mahan RJ, McCarrell J, Sleeper RB. Using a polypharmacy simulation exercise to increase empathy in pharmacy students. Am J Pharm Educ. 2018;82(3):6238. doi:10.5688/ajpe6238 10. Lor KB, Truong JT, Ip EJ, Barnett MJ. A randomized prospective study on outcomes of an empathy intervention among second-year student pharmacists. Am J Pharm Educ. 2015;79(2). doi: 10.5688/ajpe79218

11. Stoffel JM, Cain J. Review of grit and resilience literature within health professions education. Am J Pharm Educ. 2018;82(2):6150. doi:10.5688/ajpe6150

12. Pate AN, Payakachat N, Harrell TK, Pate KA, Caldwell DJ, Franks AM. Measurement of grit and correlation to student pharmacist academic performance. Am J Pharm Educ. 2017;81(6): 105. doi:10.5688/ajpe816105

13. Palisoc AJL, Matsumoto RR, Ho J, Perry PJ, Tang TT, Ip EJ. Relationship between grit with academic performance and attainment of postgraduate training in pharmacy students. Am J Pharm Educ. 2017;81(4):67. doi:10.5688/ajpe81467

14. Credé M, Tynan MC, Harms PD. Much ado about grit: a metaanalytic synthesis of the grit literature. J Pers Soc Psychol. 2017; 113(3):492-511. doi:10.1037/pspp0000102

15. Brazeau CMLR, Schroeder R, Rovi S, Boyd L. Relationships between medical student burnout, empathy, and professionalism climate. Acad Med. 2010;85(10 Suppl):S33-36. doi:10.1097/ ACM.0b013e3181ed4c47

16. Calabrese LH, Bianco JA, Mann D, Massello D, Hojat M. Correlates and changes in empathy and attitudes toward interprofessional collaboration in osteopathic medical students. $J \mathrm{Am}$ Osteopath Assoc. 2013;113(12):898-907. doi:10.7556/jaoa.2013.068 17. Schroeder SA. We can do better-improving the health of the American people. N Engl J Med. 2007;357(12):1221-1228. doi: 10.1056/NEJMsa073350

18. Van Winkle LJ, Bjork BC, Chandar N, et al. Interprofessional workshop to improve mutual understanding between pharmacy and medical students. Am J Pharm Educ. 2012;76(8). doi:10.5688/ ajpe 768150

19. Fjortoft N, Van Winkle LJ, Hojat M. Measuring empathy in pharmacy students. Am J Pharm Educ. 2011;75(6). doi:10.5688/ ajpe 756109

20. Tamayo CA, Rizkalla MN, Henderson KK. Cognitive, behavioral and emotional empathy in pharmacy students: targeting programs for curriculum modification. Front Pharmacol. 2016;7:96. doi:10.3389/fphar.2016.00096

21. Podsakoff PM, MacKenzie SB, Moorman RH, Fetter R. Transformational leader behaviors and their effects on followers' trust in leader, satisfaction, and organizational citizenship behaviors. Leadersh Q. 1990;1(2):107-142. doi:10.1016/1048-9843(90)90009-7 22. Elliot AJ, McGregor HA. A $2 \times 2$ achievement goal framework. $J$ Pers Soc Psychol. 2001;80(3):501-519.

23. Duckworth AL, Quinn PD. Development and validation of the short grit scale (Grit-S). J Pers Assess. 2009;91(2):166-174.

24. Sapp SG, Harrod WJ. Reliability and validity of a brief version of Levenson's locus of control scale. Psychol Rep. 1993;72(2):539. 25. Adler N, Stewart J. The MacArthur Scale of Subjective Social Status. MacArthur Research Network on Socioeconomic Status \& 


\section{American Journal of Pharmaceutical Education 2021; 85 (2) Article 8083.}

Health. Published March 2007. https://macses.ucsf.edu/research/ psychosocial/subjective.php. Accessed January 29, 2021.

26. Hojat M, LaNoue M. Exploration and confirmation of the latent variable structure of the Jefferson Scale of Empathy. Int J Med Educ. 2014;5:73-81. doi:10.5116/ijme.533f.0c41

27. Stansfield RB, Schwartz A, O'Brien CL, Dekhtyar M, Dunham L, Quirk M. Development of a metacognitive effort construct of empathy during clinical training: a longitudinal study of the factor structure of the Jefferson Scale of Empathy. Adv in Health Sci Educ. 2016;21(1):5-17. doi:10.1007/s10459015-9605-1

28. Hojat M, DeSantis J, Shannon SC, et al. The Jefferson Scale of Empathy: a nationwide study of measurement properties, underlying components, latent variable structure, and national norms in medical students. Adv Health Sci Educ Theory Pract. 2018;23(5):899-920. doi:10.1007/s10459-018-9839-9

29. Velicer WF, Fava JL. Effects of variable and subject sampling on factor pattern recovery. Psychol Methods. 1998;3(2):231-251. doi: 10.1037/1082-989X.3.2.231
30. Hojat M, Gonnella JS. Eleven years of data on the Jefferson Scale of Empathy-Medical Student Version (JSE-S): proxy norm data and tentative cutoff scores. Med Princ Pract. 2015;24(4):344-350. doi: $10.1159 / 000381954$

31. Berg K, Blatt B, Lopreiato J, et al. Standardized patient assessment of medical student empathy: ethnicity and gender effects in a multi-institutional study. Acad Med. 2015;90(1):105-111. doi: 10.1097/ACM.0000000000000529

32. Williams CR, Rodgers PT, McLaughlin JE, Angelo TA, Shepherd G. Comparing empathy levels in doctor of pharmacy students and exemplary pharmacist preceptors. Am J Pharm Educ. 2020;84(3):7497. doi:10.5688/ajpe7497

33. Hojat M, Zuckerman M, Magee M, et al. Empathy in medical students as related to specialty interest, personality, and perceptions of mother and father. Pers Individ Dif. 2005;39:1205-1215. 34. Wallace DS, Paulson RM, Lord CG, Bond CF Jr. Which behaviors do attitudes predict? Meta-analyzing the effects of social pressure and perceived difficulty. Rev Gen Psychol. 2005;9(3): 214-227. doi:10.1037/1089-2680.9.3.214 